\title{
Correction to: The role of doping and heating rate in optimizing the crystallization parameters of As35Se65-xSbx glasses
}

\author{
Mohamed N. Abd-el Salam ${ }^{1} \cdot$ E. R. Shaaban ${ }^{2} \cdot$ Mansour Mohamed $^{3,4}$
}

Published online: 3 September 2021

(c) The Author(s), under exclusive licence to Springer-Verlag GmbH, DE part of Springer Nature 2021

\section{Correction to: Applied Physics A}

$$
\text { https://doi.org/10.1007/s00339-021-04816-y }
$$

In this article, the affiliation details for authors were incorrectly given. The affiliations appear as below.

Mohamed N. Abd-el Salam ${ }^{1}$

${ }^{1}$ Higher Institute for Engineering and Technology, ElMinya 61768, Egypt.

E.R. Shaaban ${ }^{2}$

${ }^{2}$ Physics Department, Faculty of Science A1-Azhar University, Assiut 71542, Egypt.

Mansour Mohamed ${ }^{3,4}$

${ }^{3}$ Department of Physics, College of Science, University of Hail, P.O. Box 2440, Hail, Saudi Arabia.
${ }^{4}$ Physics Department, Faculty of Science, Assiut University, Assiut 71516, Egypt.

The original article has been corrected.

Publisher's Note Springer Nature remains neutral with regard to jurisdictional claims in published maps and institutional affiliations.

The original article can be found online at https://doi.org/10.1007/ s00339-021-04816-y.

Mansour Mohamed

m.mohamed@aun.edu.eg

1 Higher Institute for Engineering and Technology, El-Minya 61768, Egypt

2 Physics Department, Faculty of Science A1, Azhar University, Assiut 71542, Egypt

3 Department of Physics, College of Science, University of Hail, P.O. Box 2440, Hail, Saudi Arabia

4 Physics Department, Faculty of Science, Assiut University, Assiut 71516, Egypt 